\title{
SOBRE A QUESTÃO AGRÁRIA
}

\author{
José Flávio Bertero
}

Examinarei aqui, à luz da dinâmica das relações sociais de produção, as mudanças básicas verificadas no desenvolvimento recente da agropecuária brasileira. Por desenvolvimento recente da agropecuária brasileira entendo o período que se inaugura entre o final dos anos $50 \mathrm{e}$ o começo dos anos 60 e se estende aos dias atuais. Dois momentos caracterizam esse período. O primeiro deles vai de 1958-1959 a 19791980. É o momento da formação de uma nova base técnica, de origem industrial, e de um mercado de trabalho uniforme, possibilitado, em parte, pela generalização do assalariamento monetário e, em parte, pela simplificação do trabalho, decorrente do emprego da tecnologia de cunho químico-mecânica. É, pois, o momento da extensão ao meio rural das forças produtivas capitalistas e das suas correspondentes relações sociais. É, em suma, o momento da implantação no campo do modo de produção especificamente capitalista.

Esse momento, por sua vez, compreende duas fases distintas. Uma, compreendida entre os anos 1958-1959 e 1966, em que a modernização, por ser ainda localizada e tênue, é limitada, mas já denota um acentuado êxodo rural, com claros reflexos nas relações de trabalho. O colonato é praticamente extirpado da produção cafeeira. O mesmo acontece com o morador de condição ou cambão e o foreiro nordestino. (Brant, 1977; Andrade, 1966) Certamente contribuiu para isso a extensão da legislação trabalhista ao meio agrário; que, muito embora não fosse cumprida à risca, estimulou o conflito trabalhista, ao qual os fazendeiros respondiam com a racionalização do processo produtivo, sobretudo por meio da mecanização. (Piteri, 1964; Lopes, 1976; Miller Paiva, 1969a, 1969b, 1974) Intensifica-se, assim, a tendência ao assalariamento iniciado na década anterior, o que não exclui a permanência, modificadas ou não, de antigas formas, nem tampouco a reinvenção de outras formas. Que o digam os parceiros, pequenos proprietários, posseiros e outros tantos não-assalariados. (Belluzzo et 
al, [s.d.]; Gnaccarini, 1980; Silva, 1984; Lopes, [s.d.]; Müller, 1980; Miller Paiva, 1976)

Sob esse aspecto, o Estatuto da Terra (1964) revogou o Estatuto do Trabalhador Rural (1963) que, ao decretar a ilegalidade de tais formas de trabalho, vaticinou a extinção delas. Apesar disso, o Estatuto da Terra preconizava modernização agrária. Tanto assim, que em 1965, portanto um ano após a sua promulgação, criou-se o Sistema Nacional de Crédito Rural, cujo escopo era incentivar a referida modernização, o que realmente ocorre a partir de 1967 , quando se rompe com a recessão advinda do início da década de 60. É aí, em 1967-1968, que se inicia a segunda fase mencionada, a qual chega até os dias de hoje. Marca essa fase a evasão rural que conduz a um progressivo decréscimo populacional, provocado mormente pela aplicação da nova tecnologia e pela substituição das linhas produtivas tradicionais por modernas, mais bem ajustadas às demandas da indústria e do mercado externo.

São indiscutíveis os efeitos de todo esse processo sobre as relações sociais, muitas das quais cedem lugar às relações puramente assalariadas. Cresce, conseqüentemente, a proletarização. O proletariado rural ganha maior projeção. Enfim, o tão aguardado protagonista social das esquerdas entra em cena. A sua crescente presença no cenário nacional problematiza a especificidade da chamada questão agrária. Ao mesmo tempo, parecia tornar mais inteligível e transparente o destino (social e político) do país. É como se este tivesse adentrado numa nova fase da sua história. (Velho, 1980) Vale observar, a propósito, o número de artigos, dissertações, teses a ele dedicados nessa época. Tinha-se a impressão de que a proletarização era inevitável e inexorável; que tudo desaguaria nela ou conduziria a ela; que a modernização seria avassaladora e homogeneizadora; que redundaria, fatalmente, na homogeneização proletária.

Não é preciso dizer que, com isso, perdeu-se de vista a diversidade, para a qual só se voltará a atenção a contar de meados da década de 70 , ocasião em que se dá uma verdadeira reviravolta nos estudos agrários, com a ascensão do pequeno produtor e a consequiente perda da primazia atribuída ao proletário. Esse novo personagem, que ficará conhecido entre nós como camponês, erige-se, consoante muitos, no novo sujeito da história. Ele guarda uma particularidade em contraposição ao proletário. Ao contrário deste, que é produto da expansão capitalista da agropecuária e que exprime a sua contradição interna, ele é uma figura externa ao 
capital, que resiste ao seu avanço e que o nega, criando dessa forma condições para a sua superação. (Martins, 1975)

Se isso mostra, de uma parte, a tendência não homogeneizadora do desenvolvimento capitalista, de outra parte, por evidenciar a persistência de formas não-assalariadas de trabalho no meio rural, leva água ao moinho dos campesinistas, cujas vozes engrossam e se erguem, somando-se à dos reformistas, contra o caráter concentrador da estrutura fundiária e a favor da sua democratização, via reforma agrária, a qual retorna desse modo à ordem do dia. Torna-se, desde então, uma bandeira comum entre partidários da esquerda e da direita, bem como o baluarte da luta dos sem-terra, cujo movimento, à medida que alcança uma maior abrangência, deixando de ser puramente localista e passageiro, como o fora nos seus primórdios, assume uma configuração política. (Stédile, 1997; Veja, 1997, 1998)

Tudo isso sucede, contudo, no contexto de uma agropecuária renovada, melhor dizendo, intensiva, por oposição à sua precedente extensividade, que se apoiava na dobradinha terra e mão-de-obra, normalmente fartas e baratas. A extração do excedente ainda dependia do número de braços e da duração da jornada de trabalho, o que dava margem ao uso de procedimentos compulsórios. Tal fato, mais o baixo e lento grau de desenvolvimento das forças produtivas, talvez sejam explicativos da sobrevivência de grande parte das ditas relações sociais de trabalho. (Furtado, 1975; Fernandes, 1973; Oliveira, 1976)

$\mathrm{Na}$ medida em que esse grau se eleva e que a sua dinâmica se acelera (mesmo que impulsionados artificialmente pela ação estatal, que, com seus programas de racionalização e modernização e suas linhas creditícias, geralmente subsidiadas, além de seus institutos de pesquisa e serviços de extensão) a acumulação ganha velocidade e volume. Passa a depender menos das condições subjetivas e mais das condições objetivas do processo de trabalho, especialmente dos meios de produção modernos, fato que confere à organização deste processo certa cientificidade. A organização produtiva da agropecuária aproxima-se da indústria, incorpora a sua base técnica e orienta a sua produção pela sua demanda. Mais do que isso: converte-se em um dos seus ramos. Subverte, dessa forma, a sua maneira de produzir. Senão, vejamos.

Sabe-se que antes disso a acumulação dependia do montante e da qualificação da mão-de-obra. Tanto era assim, que operava como uma espécie de acumulação de trabalhadores. Não é demais esclarecer 
que se tratava de um trabalhador manual, possuidor de conhecimento, habilidade, destreza, bem como de dada capacidade física. Isso tudo o dotava de certo virtuosismo. Fazia dele um trabalhador virtuoso, que tinha na enxada, enxadão, foice, rastelo etc., ao lado do arado de tração animal, os seus instrumentos de trabalho primordiais. O emprego de produtos químicos ainda era restrito. Era a fase manufatureira da agropecuária: base técnica manual e trabalhador capaz de executar o seu trabalho com maestria, mas cuja formação, por requerer uma longa aprendizagem empírica, transmitida de geração à geração, implicava altos custos sociais, os quais oneravam a produção e limitavam a acumulação. Acresce que: a) o manejo dos instrumentos manuais torna a produção refém do virtuosismo e da força física do trabalhador; b) a baixa produtividade impõe, de um lado, a vicissitude de uma massa maior de pessoas e, de outro, a obrigatoriedade de amplas jornadas de trabalho, no geral de sol a sol. (Andrade, 1966; Furtado, 1975; Oliveira, 1976; Müller, 1980)

Um dos expedientes utilizados pelos exploradores fundiários, para fazer face à falta de braços e ao provável encarecimento da força de trabalho era o trabalho familiar, sob diversas formas. Por se valer do trabalho da mulher, dos filhos e agregados, tal trabalho age como potenciador da força de trabalho e redutor do seu custo; o seu uso é, ademais, um artifício do qual se lança mão com vistas em atrair e reter o trabalhador na propriedade. (Bertero, 1983)

Ainda assim, o capital se depara com os limites físicos do trabalhador e da duração do dia de trabalho, os quais atravancam a sua reprodução ampliada. Não só. Tão logo tomam consciência da sua exploração, graças fundamentalmente ao trabalho desenvolvido entre eles pelo Partido Comunista Brasileiro (PCB) e pela Igreja Católica, os trabalhadores passam a se organizar em sindicatos e a reivindicar direitos do trabalho. Aumentam, em decorrência disso, os conflitos entre eles e seus empregadores, aos quais estes respondem: no plano socioeconômico, com o progresso técnico e, no plano político, com a força repressora do Estado, notadamente depois do golpe militar de 1964, época em que é praticamente desmantelada toda organização trabalhista.

Há que se voltar, entretanto, ao exame do processo de trabalho. Viu-se que a base técnica equivalente à da forma manufatureira fazia com que a produção fosse dependente do trabalhador: do seu contigente e do seu virtuosismo. Essa dependência impedia a cientifização da 
organização do processo de trabalho. Em primeiro lugar, porque dependia da massa de pessoas aptas a realizar o trabalho; e, em segundo lugar, porque, se o trabalhador era assimilado ao aludido processo de trabalho, este teve antes que se adaptar àquele. O trabalho era determinante da natureza desse processo.

Por isso, não obstante se subordinasse ao capital, essa subordinação era meramente formal. Mesmo quando havia separação entre ele e os seus meios de produção, esta separação era formal. Já que, sob o prisma técnico, era ele quem dominava o elemento objetivo da produção e não o inverso. Em contrapartida, a dominação exercida pelo capital sobre o trabalho era, como se viu, formal. Fato que bloqueava a sua expansão, que só conseguia ir adiante mediante a incorporação de mais trabalhadores e de mais terras, em geral novas.

Já se observou que o Estatuto do Trabalhador Rural acelerou artificialmente a proletarização do trabalhador rural, ao decretar o fim das relações de trabalho familiar, posteriormente restauradas pelo Estatuto da Terra. Mas a tendência prevalecente não era a mesma de antes, e sim a de explorar mais racionalmente o trabalho e a terra inclusive as terras cedidas aos trabalhadores que, quando não requisitadas, tiveram a sua extensão diminuída.

A nova ordem consistia em mercantilizar o máximo as relações socioeconômicas. Isso não significa, necessariamente, a extinção das formas não-assalariadas de trabalho. Longe disso. Já se falou sobre esse ponto. $\mathrm{O}$ que se está apontando aqui é a tendência à produção de valores de troca, tendência que pressupõe o alargamento da divisão social do trabalho e, por conseguinte, a inserção da produção rurícola na produção social, na e para a qual, mais e mais, os produtores diretos produzem e da qual eles obtêm os meios de trabalho e de vida de que se servem. Daí também porque a elevação do preço da força de trabalho, cuja tendência, bem se sabe, é monetarizar-se cada vez mais. Subsumindo-se na divisão social do trabalho ou da produção social, tanto faz, os produtos, que são mercadorias, frise-se, eles não são outra coisa que não a existência objetiva da referida divisão do trabalho, a objetivação de trabalhos concretos qualitativamente diferentes, dedicados à confecção de múltiplos valores de uso, imprescindíveis à satisfação das necessidades humanas, mas que não são mais apropriados diretamente pelos seus criadores. Pois, no caso dos produtores, os produtos dos seus respectivos trabalhos concretos são valores de uso, porém não para eles e sim para 
os outros produtores, com os quais intercambiam. Os seus produtos não são, de imediato, meios de subsistência. Só se tornam isto, depois de terem adotado no dinheiro a forma de produto social, universal. Destarte, produzem somente para a sociedade, cujos membros, por sua vez, produzem para eles, noutros ramos ou segmentos da produção social. Com efeito, produzem mercadorias para outros produtores de mercadorias.

A sociabilidade capitalista chega assim ao campo. A agropecuária muda. Muda, diga-se, ampla e profundamente. Muda a forma de convivência entre as pessoas. Mas muda também, e principalmente, a sua estrutura econômico-social. É crescente, em seu meio, a produção de mercadorias por meio de mercadorias, em regra industrializadas, em escala igualmente crescente. É por intermédio da absorção destas mercadorias industrializadas que ela, agropecuária, altera a sua base técnica e, com esta, o seu modo de produzir, que se assimila ao da indústria. A essa assimilação denomina-se industrialização. Tal industrialização atinge amplamente a população rural. Ela é indubitavelmente a maior responsável pelo esvaziamento populacional do meio agrário, mediante a expulsão de trabalhadores residentes, dos quais uma parte se vê compelida a deslocarse periodicamente para o campo para nele trabalhar. São os volantes, conhecidos entre nós como bóias-frias e no Nordeste como clandestinos.

De outra parte, ao se processar, a industrialização promove a concentração da produção, do capital e da força de trabalho em determinadas linhas produtivas, estas últimas, no mais das vezes, de maneira intermitente e, por fim, paradoxalmente, da propriedade da terra. $\mathrm{O}$ excesso de gente e a sazonalidade do trabalho, que contribui para gerar, dificultam a aglomeração dos trabalhadores. A intensificação da concorrência que daí deriva divide os seus interesses. A concentração espacial da produção atua como contratendência, favorecendo a aglomeração da massa trabalhadora. A manutenção do salário e a garantia de emprego durante todo o ano - esses, interesses comuns que possuem contra os patrões - acabam por reuni-los numa mesma coletividade: o sindicato e a sua federação. Por isso, estes procuram sempre fazer cessar a concorrência entre os trabalhadores, para que eles possam competir com os seus empregadores. De modo ambíguo, é mister que se diga, pois os sindicatos incluem em suas bandeiras de lutas a reforma agrária, o que também acontece com a Comissão Pastoral da Terra (CPT). A referida comissão é um órgão da Igreja Católica que 
ensina ao trabalhador diferenciar a terra em "terra de trabalho" e "terra de negócio". Isso, convém notar, mesmo entre os assalariados e mesmo quando a terra não figura no rol das reivindicações imediatas dos trabalhadores, para não dizer que de modo geral não mais cabe a ela a responsabilidade pelas condições de existência das pessoas, mas ao capital, que a subordina, pondo-se como novo senhor do mundo agrário. Primeiro converte-a em mercadoria, depois faz dela um campo de investimento rentável. Metamorfoseia-a, dessa maneira, em terra-capital.

Retomo, contudo, a questão relativa à concorrência dos trabalhadores com os capitalistas. Tomarei, como exemplo disto, as sucessivas greves verificadas no meio canavieiro paulista na década de 80 . Se, num primeiro momento, a reivindicação dos trabalhadores é apenas econômica - salário, emprego etc.- à medida que o movimento cresce e ganha projeção, levando os empresários a se manifestarem por meio da repressão, não raro com a ajuda do Estado, como aconteceu explicitamente em 1984 e 1986, em Guariba e Leme, respectivamente, os mencionados movimentos grevistas tendem a adquirir um caráter nitidamente político. Este caráter manifesta-se não somente na amplitude assumida pelo movimento grevista após 1983 e pela maneira franca e aberta em que se deu o embate, mas também pelas conquistas obtidas pelos trabalhadores; manifesta-se na amplitude expressa na participação de mais de 100 mil trabalhadores e na propagação da greve pelo interior paulista, envolvendo várias cidades, bem como na intervenção estatal, por meio da repressão imposta pela polícia militar, da mediação de ministros e secretários, governadores, deputados etc.; manifesta-se na maneira franca e aberta de luta expressa nos incêndios, quebra-quebras, nos saques, nos piquetes, nas demissões e, acima de tudo, no corpo-acorpo com a polícia, marcado por espancamentos, ferimentos, prisões e mortes; manifesta-se por fim nas conquistas que não se resumem aos reajustes salariais e à obtenção de direitos trabalhistas, mas que se estendem à aprendizagem política. Chegando a esse ponto, a luta de classes não só aflora na superfície social, como também se explicita da maneira mais crua possível, pondo a nu a sua contradição maior; o movimento adquire assim uma configuração política, pois esta não é senão luta de classes. Também por essa via, a indústria chega ao campo. E não apenas no Estado de São Paulo. Na mesma época em que se dão as greves em São Paulo, verificam-se greves no Nordeste canavieiro, onde as reivindicações básicas são igualmente trabalhistas. 
A agricultura, sabe-se, industrializou-se. Sabe-se também que essa industrialização repercute na sua estrutura social, cuja composição se assimila cada vez mais à urbana. $\mathrm{O}$ que acarreta o estabelecimento de novas alianças e correlações de forças, em que os interesses assentados na propriedade da terra e do capital são sobrepujados pelos interesses centrados no trabalho - salários, empregos, melhores condições de trabalho e de vida etc. - , pelo lado dos trabalhadores, para quem a terra deixou de ser uma espécie de "laboratório natural", do qual extraíam diretamente parte dos seus meios de subsistência, e no capital maximização dos lucros - , pelo lado dos empresários.

A essas mudanças se ligam a desruralização da população e a urbanização do campo. No primeiro caso, verifica-se, além do esvaziamento populacional e do decorrente desenraizamento das pessoas do meio rural constatáveis, respectivamente, no decréscimo relativo e absoluto do número daquelas pessoas e na maior mobilidade delas, o estabelecimento de uma nova sociabilidade, cujos nexos sociais são dados pela forma valor, na troca, em que as pessoas são indiferentes umas em relação às outras, contando apenas e tão-somente o dinheiro que trazem em seus bolsos. No segundo caso, tem-se não só uma profunda mutação no modo de produzir, com a industrialização do agro, como nas maneiras de transportar, comercializar, consumir e até mesmo de viver. A indústria revolucionou o campo: impôs-lhe o seu modo de organizar a vida social; fez com que se submetesse a uma única e mesma dinâmica, a capitalista avançada.

Posto isso, retomo, outra vez, aquele que tem sido o fio condutor das minhas reflexões: o processo de trabalho. Procurei mostrar que, até o início dos anos 60, a agricultura era dependente do elemento humano, o qual preponderava sobre o elemento objetivo. O trabalhador permanecia como principal elemento do processo produtivo. A organização deste radicava-se em tal elemento subjetivo. A sua base técnica, similar à artesanal, baseada igualmente na ferramenta, habilmente manuseada pelo trabalhador, impossibilitava a subversão das condições de produção. A acumulação persistia extensiva, isto é, ancorada no uso extensivo da terra e da mão-de-obra, sob a hegemonia do capital comercial. Nos termos de Furtado (1975), ela ainda era "itinerante" e "predatória", o que, aliás, não era uma anomalia.

Não se tratava, porém, de pré-capitalismo. A agropecuária brasileira é, desde as suas origens, capitalista. (Prado Jr., 1972; Frank, 1969) 
A disparidade e a lentidão da sua dinâmica lhe são próprias. Quer dizer, não são senão a maneira pela qual ela se expande, sobretudo até o momento a que estou me reportando. (Silva, 1984) Todavia, o trabalho, mesmo em suas formas não-capitalistas, e a terra encontram-se em regra, se bem que formalmente, subordinados ao capital. No tocante ao trabalho, ainda quando há separação entre ele e os meios de produção, esta separação é formal, uma vez que, do pondo de vista técnico, é ele, o trabalho, quem domina o elemento objetivo da produção e não o contrário. A ausência de uma base técnica própria o impede de exercer o domínio real sobre o trabalho e, por intermédio deste, da terra.

Claro é que isso limita a sua expansão, que só ocorre mediante o acréscimo de mão-de-obra e de terras. A acumulação torna-se prisioneira desses elementos. E a extração do excedente realiza-se sob a forma de mais-valia absoluta, ou seja, por meio do prolongamento da jornada de trabalho e da sua intensificação, ao que o trabalhador, a partir de determinado momento, resiste bravamente. À baixa produtividade que disso redunda corresponde uma baixa composição do capital. Mais: sob a hegemonia do capital comercial, razão por que os interesses prevalecentes até então são os atinentes à terra e ao capital comercial.

Só a difusão do trator e dos seus acessórios, os quais darão origem ao sistema mecânico, assim como a difusão dos produtos químicos (adubos, corretivos, venenos etc.) possibilitarão a ruptura com essa situação. A adoção dessa tecnologia subverte a produção. De agora em diante, as modificações do processo de trabalho partirão dos meios de produção e não mais do trabalhador. Tampouco este prosseguirá manipulando tais meios. Restringir-se-á a vigiá-los. Adaptar-se-á ao processo de trabalho, em vez de adaptá-lo a si. O trator, seus implementos e demais equipamentos que logo advirão, tomam o seu lugar. $\mathrm{O}$ seu virtuosismo desloca-se para tais elementos e para os produtos químicos, que junto com eles constituem os elementos objetivos do processo produtivo. Seu virtuosismo é incorporado pelos elementos materiais. São esses os novos virtuosos. O seu saber-fazer lhe é expropriado e substituído por um novo saber, o técnico-científico, o qual, além de não lhe pertencer, escapa do seu controle. Esse novo saber cristaliza-se nos referidos elementos materiais ou objetivos. Ao trabalhador, resta então executar tarefas cada vez mais simples como carpir (quando não se usa herbicida), cortar cana, colher algodão, apanhar laranja, colher café etc., enquanto não se mecanizam plenamente as suas colheitas. $\mathrm{O}$ que, a

Rev. Mediações, Londrina, v. 5, n. 1, p. 109-122, jan./jun. 2000 
despeito de ainda requerer dele certa habilidade e destreza, não mais exige de sua parte uma ampla aprendizagem. Esse fato faz com que perca a sua anterior qualificação e, portanto, o seu virtuosismo. A industrialização do campo o desqualifica. Ao fazer isso, simplifica o seu trabalho, efetivando o seu caráter abstrato. Nessas condições, são os meios de produção que determinam e regulam a ação do trabalhador. São esses meios que o acionam; imprimem-lhe o tom e o ritmo; sua ação reduz-se à mera abstração. Nisso reside o segredo da sua mobilidade por entre as várias atividades rurais e urbanas, suposto e resultado da unificação do mercado de trabalho. (Brant, 1977; Bertero, 1983)

A essa unificação seguem-se outras, a saber: a do mercado de bens de produção, a do mercado de bens de consumo e a do mercado de capital. Tal unificação dos mercados redefine a relação entre cidade e campo; redefinição essa, vale dizer, que consiste na urbanização deste. Assim é que, ao incorporar a base técnica industrial, o campo se industrializa; e ao unificar os seus mercados, assimilando os padrões técnico-econômico e sociocultural urbanos, ele se urbaniza. Percebe-se, pois, que as suas transformações não são somente técnico-econômicas, mas também sociais, visto que se verificam mudanças nas relações de trabalho com claros reflexos na estrutura social, a qual se unifica; e, ainda, culturais, porque o modo de vida rural é assimilado ao urbano.

Haja vista o contingente de trabalhadores que ascende à condição de cidadãos desse mundo mercantilizado como portadores de força de trabalho, com a qual comparecem no mercado, a fim de vendê-la, recebendo, em troca, uma quantia em dinheiro, seus salários. São, quase sempre, expropriados de meios de trabalho e de vida, bem como do saber que possuem; expropriação esta, reitera-se aqui, provocada pela inovação tecnológica em curso; motivo pelo qual o trabalho deles se torna realmente simples e indiferenciado, ou seja, abstrato; o que lhes permite exercer qualquer função, às vezes com pequeno preparo, e que thes confere identidade de classe, em nível mais fundo que o conferido pelo salário, por exemplo, que é uma categoria empírica, típica da superfície social. É nessas circunstâncias que são trocadas experiências e elaboradas estratégias de vida. Ao lado disso, aprendizagens de luta operária são assimiladas, seja através de educação política (sindicatos, partidos etc.), seja ainda por intermédio dos meios de comunicação modernos (rádio, televisão, cinema, vídeo, jornais, revistas, panfletos etc.). Da interação desses elementos resulta a formação de uma cultura 
nova, essencialmente urbana, que nada mais tem a ver com o rural, a não ser o local de consumo da força de trabalho, que é uma fazenda ou sítio, porém, desde algum tempo, convertidos em empresas e por isso mesmo orientados para o lucro. As fazendas constituem-se empresas, pura e simplesmente, os sítios, empresas familiares. Os seus proprietários são, em regra, capitalistas, os quais se diferenciam entre si de acordo com o montante de seus respectivos capitais.

Compreende-se, assim, porque os trabalhadores rurais, particularmente os assalariados, fixos e volantes, tendem a se aproximar mais, em suas reivindicações e lutas, dos operários urbanos. Os seus interesses tornaram-se comuns. E a razão disso é simples: sem desconsiderar a existência de diferenças internas nos assalariados rurais (proletários, semiproletários, basicamente), não é absurdo dizer que ambos são operários. (Müller, 1978) Quem os explora e domina é o capital e não mais a terra. É aquele que a todos e a tudo domina, incluindo-se a terra. E se ainda há os que se aferram a esta velha senhora, não é porque resistem ao avanço daquele novo senhor, e sim à ameaça de proletarização. Ao apoderar-se de todos e tudo, o capital erige-se no novo senhorio. Mas, ao fazer isso, assume a condição de principal opositor do trabalho.

Ora, tal acontecimento impõe ao trabalhador a necessidade de ruptura com a velha aliança, estabelecida em função da terra e do capital comercial. A aliança tende a se fazer agora em relação ao adversário comum dos trabalhadores, quer-se dizer, do capital, e não mais da terra, conforme continuam pensando e apregoando muitos, aí incluídos sindicalistas, membros de federações e das confederações dos mencionados trabalhadores, partidos políticos etc., sendo esta, aliás, a posição majoritária em tais instituições.

Pelo que se supõe, essa tendência deverá romper a aliança geral a que os trabalhadores rurais estão submetidos no sindicalismo brasileiro. Tudo indica que, ao se aprofundarem as transformações no campo e elevar-se o nível de organização e consciência dos trabalhadores, especialmente os assalariados, o acesso à terra não mais poderá permanecer figurando como bandeira unitária do sindicalismo. Não por acaso as greves têm priorizado os salários e os direitos trabalhistas, os quais não passam pelo acesso à terra, mas pela luta contra os mandos e desmandos do capital. A própria terra é, segundo se viu, convertida em capital, razão pela qual a sua reivindicação é extemporânea. Não mais condiz 
com a existência do trabalhador. Se a terra ainda é capaz de aglutiná-los e mobilizá-los, é porque age normalmente como refúgio de desempregados.

Viu-se que, de modo geral, os produtores são mercantis; que, no mais das vezes, os seus trabalhos pertencem ao trabalho coletivo, do qual não são mais que um simples órgão; viu-se, além disso, que por esse motivo só podem apropriar-se do produto dos seus trabalhos sob as formas sociais de salário, renda e lucro. Não é mais o trabalho que lhes garante a apropriação, mas a posse de meios de produção, os quais no geral revestem a forma de capital, cuja valorização depende da taxa média de lucro. A mesma coisa sucede com a terra, de cujo produto só poderá apropriar-se sob a forma de renda. Isso, mesmo em se tratando de uma forma de produção não-capitalista, ainda que neste caso muitas vezes o produtor o faça por analogia ou idealmente.

E se tal apropriação não acontece, não é porque o produtor está à margem da produção social, mas porque a produtividade com a qual opera a inviabiliza. Quando isso ocorre, o que é freqüente, não valoriza nem o seu capital nem a sua terra. Não efetiva, portanto, a propriedade econômica dos meios de produção de que é portador, dentre os quais se inclui, é bom explicitar, a terra. Constantemente, aliás, não só não os valoriza como se descapitaliza e se endivida. A dívida bate-lhe, assim, às portas. Faz-se refém dela. Logo, do capital a que se subordina: bancário, usurário. Quando não, do capital comercial ou industrial. Obriga-se, em consequiência disso, a comprimir os gastos de reposição, mesmo os pessoais. Evidencia-se o seu empobrecimento. A saída que lhe resta é o assalariamento temporário, seu e de membros da sua família, a qual se decompõe. Casos há em que arrenda ou vende a terra ou ainda a abandona e migra para a cidade. No primeiro caso, é um semiproletário; nos últimos casos, um proletário. Os que vivem somente de seus pequenos negócios são pequenos capitalistas. Porém, todos eles pertencem à estrutura de classes da sociedade. A menos que se queira ser arbitrário com a realidade social, não há razão, pois, para se falar em camponês. Muito menos para considerá-lo como o portador do futuro, isto é, como o novo sujeito da história. Tampouco para se atribuir ao campo uma questão própria, específica, posto que, a meu ver, é à luz das classes sociais que se deve pensar a questão política. Assim vista, a propalada questão agrária não se justifica. A questão que aflige o trabalhador rural hoje é similar a do trabalhador urbano. Fato que os irmana. 
ANDRADE, M. C. A terra e o homem no Nordeste. São Paulo: Brasiliense, 1966.

BELLUZZO, L.G.M. et al. Comercialização e formação de preços. Campinas: Universidade Estadual de Campinas, [s.d.].

BERTERO, J.F. Parceiros do rio Pardo: um estudo do processo de trabalho na cultura de cebola. Campinas, 1983. Dissertação (Mestrado em Sociologia) - Universidade Estadual de Campinas.

Estado, agricultura e agroindústria. São Paulo, 1991. Tese (Doutorado em Sociologia) - Universidade de São Paulo.

BRANT, V.C. Do colono ao bóia-fria: transformação na agricultura e constituição do mercado de trabalho na Alta Sorocabana de Assis. Estudos Cebrap, São Paulo, n.19, jan./fev./mar. 1977.

FERNANDES, F. Anotações sobre o capitalismo e a mudança social no Brasil. In: SZMRECSÁNY, T. et al. (org.). Vida rural e mudança social. São Paulo: Companhia Editora Nacional, 1973.

FRANK, A.G. Desenvolvimento do subdesenvolvimento. In: PEREIRA. L. (org.) Urbanização e subdesenvolvimento. Rio de Janeiro: Zahar, 1969.

FURTADO, C. Estrutura agrária no subdesenvolvimento brasileiro. In: Análise do modelo brasileiro. Rio de Janeiro: Civilização Brasileira, 1975.

GNACCARINI, J. C. Latifúndio e proletariado: formação da empresa e relação de trabalho no Brasil rural. São Paulo: Editora Polis, 1980.

LOPES, J.R.B. Empresas e pequenos produtores no desenvolvimento do capitalismo agrário em São Paulo. Estudos Cebrap, São Paulo, n.22, [s.d.].

Do latifúndio à empresa: unidade e diversidade do capitalismo no campo. Cadernos Cebrap, São Paulo, n.26, 1976.

MARTINS, J. S. A militarização da questão agrária no Brasil. Petrópolis: Vozes, 1975. Cap. 4.

MILLER PAIVA, R. Apreciação geral sobre o comportamento da agricultura. Revista de Administração Pública, Rio de Janeiro, 1969a.

. Reflexões sobre as tendências da produção, da produtividade e dos preços do setor agrícola do Brasil. In: Agricultura subdesenvolvida. Petrópolis: Vozes, $1969 \mathrm{~b}$.

O processo de modernização agrícola e o dualismo tecnológico nos países em desenvolvimento: o caso do Nordeste seco brasileiro. Belo Horizonte: UFMG, out. 1974. mimeo.

O setor agrícola no Brasil. Rio de Janeiro: Forense, 1976.

MÜLLER, G. Estado, estrutura ag rária e população: estagnação e incorporação regional. Petrópolis: Vozes, 1980. 1978.

(coord.) Trabalho volante na agricultura paulista. SEADE, São Paulo, n.25, 
OLIVEIRA, F. A economia brasileira: crítica à razão dualista. In: Questionando a economia brasileira. São Paulo: Brasiliense, 1976.

PITERI, A.D. O Estatuto do Trabalhador Rural: problemas de aplicação e prováveis conseqüências sócio-econômicas. Agricultura em São Paulo, ano 11, ns.1 e 2, jan./ fev. 1964.

PRADO JÚNIOR, C. A revolução brasileira. São Paulo: Brasiliense, 1972.

SILVA, S. Estudo sobre a estrutura da produção e a questão agrária. Cadernos IFCH 12 , Campinas, UNICAMP, 1984.

STÉDILE, Y.P. (org.) A reforma agrária e a luta do MST. Petrópolis: Vozes, 1997.

VEJA. A marcha dos radicais: quem são e o que querem os sem-terra. São Paulo, ano 30, n. 15,16 abr. 1997.

Eles chegaram lá: o que fazer agora?. São Paulo, ano 30, n.16, 23 abr. 1997. . O que eles querem. São Paulo, ano 30, 3 jun. 1998.

VELHO, O.G. A propósito: de terra e Igreja. Encontros com a Civilização Brasileira, n.22. Rio de Janeiro, 1980.

RESUMO

O presente texto é um estudo sobre a chamada questão agrária no Brasil. Trata-se de um estudo crítico, com base nas transformações recentes da agropecuária, que conclui pela inexistência de uma questão agrária específica.

Palavras-chave: trabalho; capital; terra; subordinação; classes sociais.

\section{ABSTRACT}

The present text is a study about the so called agrarian question in Brazil. It is a critical study based on recent changes in agriculture, showing the inexistence of a specific agrarian question.

Key words: labour; capital; land; subordination; social classes.

José Flávio Bertero é professor de Sociologia do Departamento de Ciências Sociais da UEL. 